\section{US on track for stabilization}

\section{Washington}

TOTAL US greenhouse gas emissions will be at about the same level in 2000 as they were in 1987, even with no efforts at control beyond those already planned, a federal official said last week in Washington at a government conference on global change.

Alexander Cristofaro, director of the air and energy policy division of the Environmental Protection Agency (EPA), released results of a study showing that existing policies such as the regulations governing garbage landfills will have sufficient impact on production of greenhouse gases to counteract the expected increases in carbon-dioxide emissions by the end of the century.

The EPA study uses a "carbon equivalency" calculation (first developed by the Intergovernmental Panel on Climate Change [IPCC] for its report earlier this year) to compare the relative atmospheric impact of carbon dioxide, CFCs, methane and other greenhouse gases. $\mathrm{Cal}$ culating the time these gases remain in the atmosphere, the EPA arrived at total 1987 US emissions equivalent to 2,328 million tonnes of carbon. By 2000, carbon-dioxide emissions will have gone up, but CFCs and methane will be down and other gases will remain relatively constant, thanks to regulations already in place. Total emissions at the turn of the century will be 2,332 tonnes - almost unchanged from the 1987 levels.

US officials hailed the figures as a triumph for the administration's "no regrets" environmental policy - the position that, in the absence of clear evidence that the greenhouse effect is upon us, the government should commit itself only to climate-change measures that have other benefits such as pollution control or energy efficiency.

Should the measured increase in global temperatures be due to something other than global warming, such measures and their economic and social costs - will not have been in vain, presidential science adviser D. Allan Bromley argues in an article in this month's Issues in Science and Technology.

But environmentalists warn that the EPA study makes over-optimistic assumptions about the energy-efficiency incentives of the Clean Air Act and underplays the fact that emissions will rise considerably above 1987 levels during the 1990s before many of the policies have a chance to show an effect. And both critics and the EPA note that after 2000, total US emissions head for the stratosphere reaching 2,430 million tonnes by 2010 unless the United States adopts additional policy measures.

Nevertheless, the EPA report does show that initial reductions can be achieved at minimal additional cost. And although the IPCC carbon-equivalents methodology may be in some ways flawed (it does not, for example, take into consideration sulphur dioxide, which is the principal industrial cause of acid rain, but may counter global warming by increasing the reflectivity of clouds), "it's probably the best we can do at the moment", says William Nitze, a former State Department official who is now president of the Alliance to Save Energy, "I don't think it's biased in any particular direction."

The most significant conclusion, he points out, is that President Bush could announce tomorrow that the United States would commit itself to achieving no more than 1987 total greenhouse gas levels by the year 2000, and it would cost him virtually nothing. Will Bush make such a declaration, perhaps in time for this week's World Climate Conference in Geneva? "Don't count on it", says one National Oceanic and Atmospheric Administration (NOAA) official. Without the backing of the other industrialized nations, he says, the United States is reluctant to make any promises

\section{Melbourne}

THE Australian government has agreed to stabilize at 1988 levels the emission of greenhouse gases by the year 2000 and to reduce them by 20 per cent by the year 2005 , provided there is no damage to the Australian economy or to industry's international competitiveness. The agreement does not include the greenhouse gases, principally CFCs, that are already scheduled to be phased out under the Montreal Protocol and is thus considerably more ambitious than plans being put forward in the United States (see above).

The Minister for the Environment, Ros Kelly, will take Australia's commitment to the Second World Climate conference in Geneva on 6 November, stressing that Australia will act only if other countries adopt similar targets.

Australian industry is not confident that the targets can be met without considerable harm. According to David Nolan, director of the Confederation of Australian Industry, there may not be an overall effect on the economy, but individual industries will suffer from the 20 per cent cut. "It's impossible for the power industry, for instance, not be affected."

The Industry Commission will assess the cost of the 20 per cent reduction target to industry and will report to the government by the end of 1991 . But this week,

that it might someday regret if the scientific assumptions of greenhouse warming change.

Others have a different explanation. "The administration has always felt that target-setting is a slippery slope and they don't want to get started down it", says Alan Miller, of the University of Maryland's Centre for Global Climate Change.

Achieving 1987 emissions level in 1990 is encouraging, but even the most conservative administration officials recognize that more needs to be done if the greenhouse effect is real. Cumulative atmospheric totals of greenhouse gases are the quantities to worry about most, and continuing to pump an equivalent of over 2,000 million tonnes of carbon into the atmosphere each year will not reduce atmospheric concentrations, or slow global warming.

Indeed, few expect a strict no-regrets policy to be around for long, especially if scientific evidence continues to point to a climate on the verge of disaster. The NOAA official concedes that "all these current environmental measures fit into the no-regrets policy. But how many more of these things we can find if faced with global warming remains to be seen."

Christopher Anderson

\title{
Australia sets example
}

the Department of Primary Industry and Energy announced a series of programmes designed to bring about immediate reductions in greenhouse gas emissions.

Focusing on the consumer, the measures aim to reduce Australia's annual energy bill by $A \$ 1,500$ million by 2005 and to reduce greenhouse gas emissions by 14,200 kilotonnes of carbon dioxide each year. Information kits on energy conservation will be distributed to each household; all government housing and commercial buildings will have energy managers and will be built using energy-efficient technology and all government depariments and agencies will be required to report annually on their energy use and energy efficiency.

In $1986-87$, according to George Wilkenfeld, an energy consultant to state and federal governments, Australia produced 279,000 kilotonnes of carbon dioxide, 6,400 kilotonnes of methane and 300 kilotonnes of nitrous oxide.

Wilkenfeld believes that the bulk of the 20 per cent reduction can be achieved only through the cooperation of industry. "Energy-efficient measures, used in industry, can cut carbon dioxide emissions by up to 30 per cent. The first 20 per cent reduction can actually be achieved at a profit because of the savings in power wastage." 